\title{
Erythromycin induces supranormal gall bladder contraction in diabetic autonomic neuropathy
}

\author{
S M Catnach, A B Ballinger, M Stevens, P D Fairclough, R C Trembath, P L Drury, \\ P J Watkins
}

\begin{abstract}
Gall bladder motor function is impaired in some patients with diabetes. It has been suggested that the abnormalities of gall bladder motility are confined to those patients with autonomic neuropathy. Erythromycin, a motilin receptor agonist, causes gall bladder contraction in both normal subjects and patients with gall stones with impaired gall bladder emptying. The effect of erythromycin on gall bladder motility in seven patients with diabetes with an autonomic neuropathy, six patients with diabetes without autonomic neuropathy, and 17 normal subjects was studied using ultrasound. There was no significant difference in gall bladder fasting volume between the three groups, but the patients with diabetes with autonomic neuropathy had impaired postprandial gall bladder emptying compared with normal subjects (percentage emptied (SEM) $40(10.3) \%$ v $64(2.8) \%$, $\mathbf{p}<0.01)$ and those with autonomic neuropathy (48 $(7 \cdot 7) \%$, NS). Erythromycin produced a dramatic reduction in gall bladder fasting volume in patients with diabetes with an autonomic neuropathy, compared with either normal subjects or patients with diabetes without autonomic neuropathy (percentage reduction $62(4.6) \%$ in patients with autonomic neuropathy, $v 37(17.6) \%$ in those without autonomic neuropathy, and $26(7 \cdot 3) \%$ in the normal subjects, $(p<0.02)$ and returned gall bladder emptying to normal in all patients with impaired emptying. The pronounced effect of erythromycin in diabetic autonomic neuropathy suggests denervation supersensitivity and that the action of erythromycin on the gall bladder is neurally modulated.

(Gut 1993; 34: 1123-1127)
\end{abstract}

Departments of

Gastroenterology

S M Catnach

A B Ballinger

P D Fairclough

and Endocrinology, St

Bartholomew's Hospital,

London

R C Trembath

Department of Diabetic Medicine, King's College Hospital, London

M Stevens

P L Drury

P J Watkins

Correspondence to:

Dr P D Fairclough,

Gastroenterology

Department, $\mathrm{St}$

Bartholomew's Hospital, Wes

Smithfield, London ECIA

7BE

Accepted for publication 24 November 1992
Erythromycin, and some of its analogues, are potent motilin receptor agonists and will stimulate gastrointestinal motor activity in many species, including man. 'It has been suggested, however, that not all of the effect of erythromycin on gastrointestinal motility is mediated by the motilin receptor as some of the actions of erythromycin are dissimilar to those of exogenous motilin. ${ }^{2}$ Erythromycin will change the cycle length of the migrating motor complex in progress and, at high doses cause giant retrograde antral contractions and clustered contractions in the duodenum. None of these phenomena have been described with motilin. We have shown that oral erythromycin will provoke gall bladder contraction in man, in both normal subjects and those with gall stone disease, although the exact mechanism is unclear. ${ }^{3}$ There is, however, some preliminary evidence that cholinergic mechanisms play a part in the action of erythromycin on the small intestine and the gall bladder. ${ }^{45}$

Gall bladder motor function abnormalities have been described in patients with diabetes. Gitelson et $a l^{6}$ were the first to report that diabetic patients have larger gall bladders than normal and this has also been confirmed by other groups. ${ }^{7}$ In addition it has been reported that postprandial gall bladder contraction is impaired, and that these abnormalities are confined to those patients with autonomic neuropathy.$^{8-10}$

We have investigated the effect of oral erythromycin on gall bladder fasting volume and postprandial gall bladder emptying in diabetic patients with and without an autonomic neuropathy and compared this with the action of erythromycin on gall bladder motility in normal subjects.

\section{Methods}

\section{SUBJECTS}

Diabetic patients were recruited from the Department of Diabetic Medicine, King's College Hospital, London. None had any history or symptoms of gall stone disease and none were taking any drugs apart from insulin or oral hypoglycaemic agents. Two groups of diabetic patients were studied.

\section{GROUP A}

Seven diabetic patients with autonomic neuropathy. Their median age was 52 years (range 4869), four of whom were women. The presence of autonomic neuropathy was defined according to the following criteria ${ }^{11}$ : (i) heart rate variability on six maximal respiratory efforts of less than 10 beats per minute; (ii) abnormal heart rate response to the Valsalva manouvre (that is, a ratio of less than 1:1.15; (iii) heart rate increase of less than 10 beats per minute on standing; (iv) a fall in systolic blood pressure on standing of more than $20 \mathrm{~mm} \mathrm{Hg}$.

GROUP B

Six diabetic patients median age 50 years, range (38-62), three women, in whom the presence of autonomic neuropathy had been excluded.

The Table gives details of the patients. All of the patients with autonomic neuropathy had abnormal autonomic function tests as defined above. Two subjects had a normal Valsalva ratio but other tests of autonomic function were abnormal. 
Characteristics of diabetic patients. Medians and ranges are given

\begin{tabular}{lcc}
\hline Variable & $\begin{array}{l}\text { Without autonomic neuropathy } \\
(n=6)\end{array}$ & $\begin{array}{l}\text { With autonomic neuropathy } \\
(n=7)\end{array}$ \\
\hline Gender (men, women) & $3: 3$ & $3: 4$ \\
Age in years & $50(38-62)$ & $52(48-69)$ \\
NIDDM/IDDM & All IDDM & 1 NIDDM \\
Duration diabetes (years) & $26(12-39)$ & $33(2-52)$ \\
Heart rate variability (beats/min) & $23(16-25)$ & $3(1-6)$ \\
Valsalva ratio & $1 \cdot 37(1 \cdot 25-1 \cdot 52)$ & $1 \cdot 07(1 \cdot 0-1 \cdot 4)$ \\
\hline
\end{tabular}

${ }^{\star} \mathrm{NIDDM}=$ Non-insulin dependent diabetes. IDDM $=$ Insulin dependent diabetes.

Seventeen normal volunteers, median age 37 years, range 23-64 years, six women, were recruited from hospital staff. None had any history of gastrointestinal or gall bladder disease and ultrasonography showed no evidence of gall bladder abnormality.

All subjects gave informed consent and the study was approved by the Research Ethics Committee of the City and Hackney Health Authority, London.

MEASUREMENT OF GALL BLADDER VOLUME

Gall bladder volumes were measured by ultrasound..$^{12}$ Using a $3.5 \mathrm{MHz}$ transducer, real time ultrasound scans were obtained with an Aloka SSD 500 scanner. Subjects were scanned supine in the right anterior oblique position and gall bladder visualised in the longitudinal and transverse planes. Measurements of the maximum length, width, and height were taken and recorded in duplicate. The volume of the gall bladder was subsequently calculated using the ellipsoid method (volume $=0.52 \times$ length $\times$ width $\times$ height $).{ }^{13}$

PROTOCOL

Patients with insulin dependent diabetes were instructed to reduce their evening dose of longacting insulin by two units before the study, and to omit the morning dose of insulin. Non-insulin dependent diabetic patients were instructed to omit the morning dose of oral hypoglycaemic agent. Fasting blood glucose was determined from a venous blood sample.

Erythromycin stearate $500 \mathrm{mg}$ (Abbott) or placebo was taken orally at 6 am in a double blind randomised fashion, with a sip of water if necessary. Scans were performed at 8 am after a 10 hour fast. The fasting volume (FV) of the gall bladder was calculated from the mean of two sets of measurements taken five minutes apart. Subjects then drank $250 \mathrm{ml}$ of a proprietary enteral feed (Ensure, $250 \mathrm{Kcal}, 8.8 \mathrm{~g}$ of fat as corn oil, Abbott Laboratories, Berks, England), and the gall bladder was rescanned at five minute intervals for $\mathbf{4 0}$ minutes.

\section{VARIABLES OF GALL BLADDER FUNCTION}

Gall bladder FV describes the volume of the gall bladder before the meal. After ingestion of the liquid test meal, the smallest volume obtained is termed the residual volume (RV). The percentage of gall bladder emptying after the meal (maximal percentage emptied) was equal to $(1-\mathrm{RV} / \mathrm{FV}) \times 100 \%$. Gall bladder

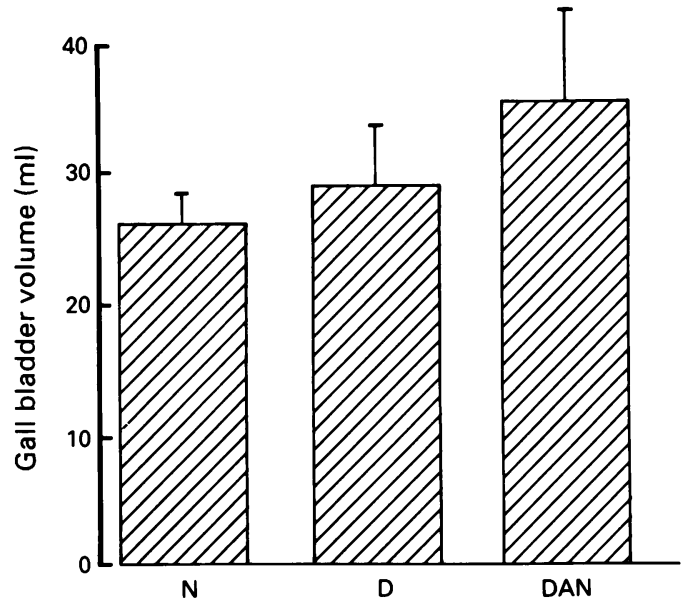

Figure 1: Gall bladder fasting volumes in normal subjects $(N)$, diabetic patients without autonomic neuropathy $(D)$, and diabetic patients with autonomic neuropathy (DAN). There is no significant difference between the three groups.

emptying was assumed to obey the first order exponential function $V_{t} / V_{0}=e^{-b t}$, where $V_{t}$ is gall bladder volume at time $t, V_{0}$ is initial gall bladder volume, and $b$ is the rate constant of emptying. ${ }^{14}$ The rate constant of emptying can be calculated from the linear regression of $\ln$ gall bladder volume $v$ time.

\section{STATISTICS}

Results are expressed as the mean and standard error of the mean (SEM). Differences between groups were tested for statistical significance by the Wilcoxon rank sum test, with $\mathrm{p}<0.05$ taken as significant. Paired data within each group were compared using the Wilcoxon signed rank test.

\section{Results}

One patient in each of the diabetic groups had gall stones. Both were asymptomatic with no evidence of gall bladder wall thickening.

Although there was a trend for increased fasting gall bladder volume in the diabetic groups compared with normal subjects, this did not reach significance (Fig 1). Diabetic patients with autonomic neuropathy had impaired gall bladder emptying after the test meal, compared with normal controls (mean maximal percentage emptied $40(10 \cdot 3) \% v 64(2 \cdot 8) \%, \mathrm{p}<0.01)$, but there was no significant difference between normal subjects and diabetic patients without autonomic neuropathy (maximal percentage emptied $64(2 \cdot 8) \% v 48(7 \cdot 6) \%$ respectively). Within both diabetic groups, however, there were some patients with impaired postprandial gall bladder emptying $(>2 S \mathrm{SD}$ from the mean of the normal controls) (Fig 2).

Reduced gall bladder emptying in those with autonomic neuropathy was reflected in a trend towards increased mean postprandial residual gall bladder volume $(20 \cdot 7(7 \cdot 7) \mathrm{ml})$, compared with diabetic patients without autonomic neuropathy $(15.6(3.6) \mathrm{ml})$ and normal subjects $(9.0$ $(0.9) \mathrm{ml})$, although this failed to reach significance.

The rate constant of postprandial emptying 


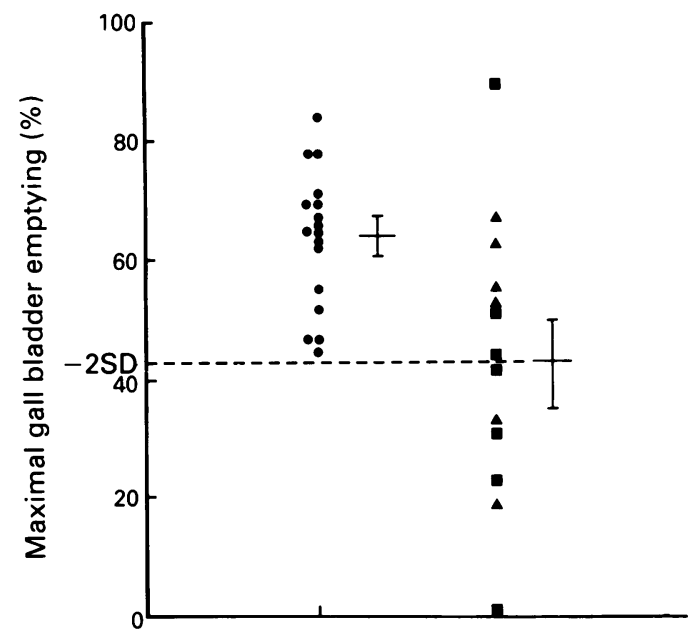

Figure 2: Maximal percentage gall bladder emptying in normal subjects $(\mathbf{O})$, diabetic patients without autonomic neuropathy $(\mathbf{\Delta})$, and diabetic patients with autonomic neuropathy (- Means and SEM of the groups are shown. The dotted line represents -2 standard deviations from the mean of the normal subjects.

was significantly reduced in both groups of diabetic patients compared with normal subjects. (Rate constant of gall bladder emptying -0.024 $(0.013) / \mathrm{min}$ in diabetic patients with autonomic neuropathy, and $-0.026(0.017) / \mathrm{min}$ in those without autonomic neuropathy, compared with $-0.04(0.004) / \mathrm{min}$ in normal subjects, $\mathrm{p}<0.05)$.

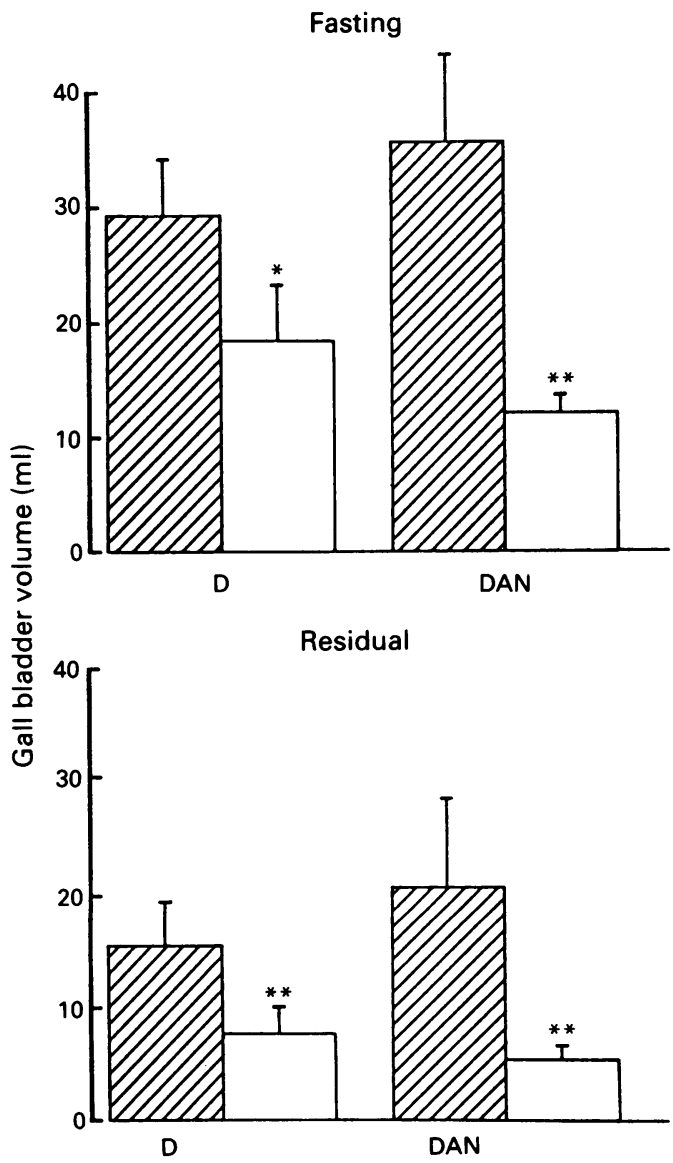

Figure 3: Gall bladder fasting and residual volumes in diabetic patients without $(D)$ and with autonomic neuropathy $(D A N)$, after placebo (hatched bar) and oral erythromycin $500 \mathrm{mg}$ (plain bar). ${ }^{\star} p<0.05$ placebo $\mathrm{v}$ erythromycin. $\star \star p<0.01$ placebo $\mathrm{v}$ erythromycin.

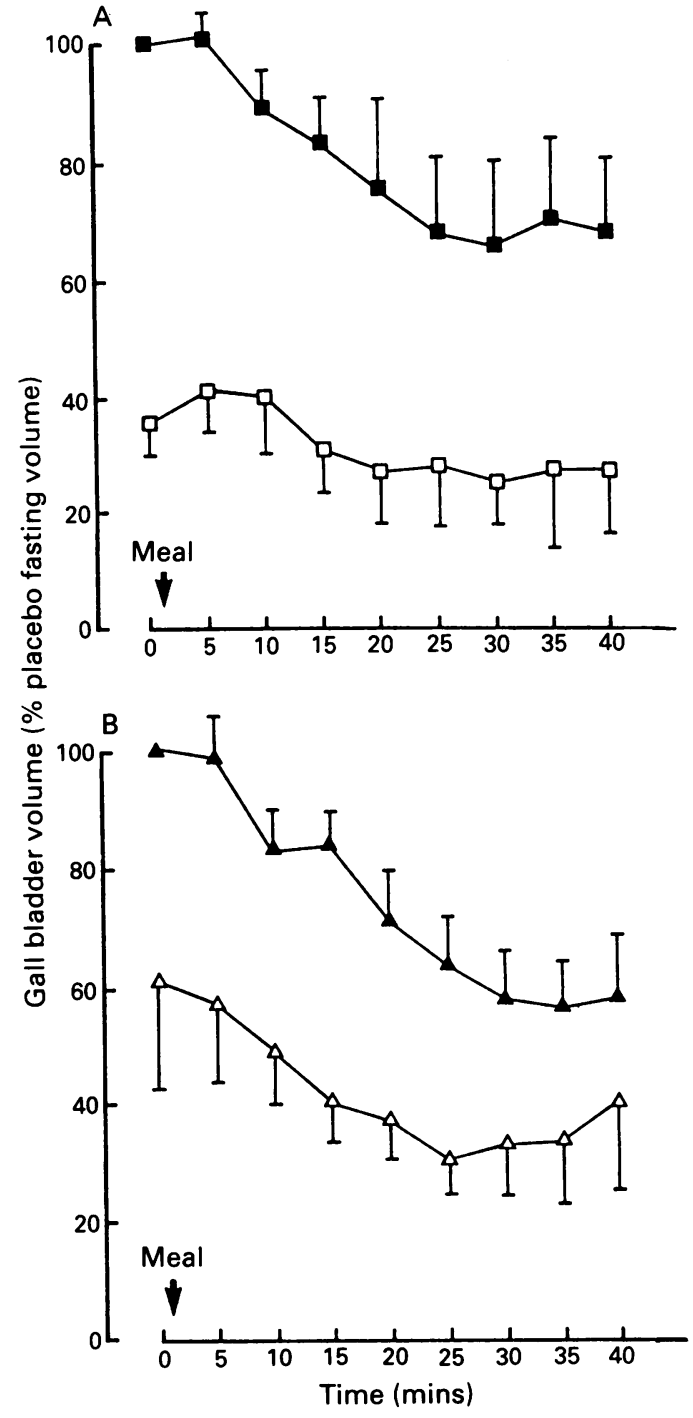

Figure 4: Meal stimulated gall bladder emptying after placebo $(\Delta / \square)$ and oral erythromycin $500 \mathrm{mg}(\triangle / \square)$ in $(A)$ patients without autonomic neuropathy and $(B)$ patients with autonomic neuropathy. Means and SEM are shown.

Erythromycin had a profound effect on gall bladder fasting volume in both groups of diabetic patients, but its effect was especially noticeable in those with an autonomic neuropathy. Percentage reduction in gall bladder fasting volume in diabetic patients with autonomic neuropathy, 62 $(4 \cdot 6) \% v(17 \cdot 6) \%$ in those without autonomic neuropathy and $26(7 \cdot 3)$ in the normal subjects. The percentage reduction in fasting volume was significantly greater in those with autonomic neuropathy compared with the other two groups, $\mathrm{p}<0.02)$. Gall bladder postprandial residual volume was dramatically reduced in both groups of diabetic patients by erythromycin. (In diabetic patients with autonomic neuropathy, postprandial residual volume was reduced from $20.7(7 \cdot 7) \mathrm{ml}$ to $5 \cdot 2(1.0) \mathrm{ml}$, $\mathrm{p}<0.01$; diabetic patients without autonomic neuropathy, $15.6(3.6) \mathrm{ml}$ to $7.8(2.3) \mathrm{ml}$, $\mathrm{p}<0.01$ ) (Fig 3).

Figure 4 shows the time course of the action of erythromycin on postprandial gall bladder emptying. In contrast with the effect on gall bladder fasting volume, erythromycin had a similar effect on meal stimulated gall bladder emptying in diabetic patients with autonomic 
neuropathy, those without autonomic neuropathy and normal subjects. The rate constant of gall bladder contraction was unchanged in either diabetic group by erythromycin. (Diabetic patients with autonomic neuropathy -0.024 $(0.013) / \mathrm{min} v-0.026(0.009) / \mathrm{min}$. Diabetic patients with autonomic neuropathy -0.026 $(0.017) / v-0.023(0.015) / \mathrm{min})$.

\section{Discussion}

We have found that fasting gall bladder volume was similar in both groups of diabetic patients but the diabetic patients with autonomic neuropathy had impaired gall bladder emptying after the meal compared with those without autonomic neuropathy, at least after the liquid meal stimulus used in these studies. This may be consequent upon delayed gastric emptying due to diabetic gastroparesis changing nutrient delivery to the duodenum and therefore release of cholecystokinin, although the time course of gall bladder emptying was normal. If gastric stasis was responsible for the poor gall bladder emptying, one might expect that gall bladder contraction after the meal would be delayed. Other workers have also described impaired gall bladder emptying in response to a meal stimulus in diabetic patients and most data would suggest that this emptying defect is confined to those with autonomic neuropathy.$^{8-10}$ There is evidence of cholinergic nerve damage in these patients, as the cephalic phase of gall bladder emptying that is mediated by cholinergic pathways has been shown to be abnormal in these patients. ${ }^{15}$

Lithogenic bile with cholesterol supersaturation is a prerequisite for cholesterol gall stone formation. Many normal subjects without gall stones, however, also have supersaturated bile and other factors must be therefore involved. ${ }^{16}{ }^{17}$ There are several strands of evidence to suggest that impaired gall bladder motility is implicated in the pathogenesis of cholesterol gall stones. Firstly, experimental evidence in prairie dog, a model of cholelithiasis, has shown that a gall bladder motility defect comes before gall stone formation ${ }^{18}$ and the propensity to stone formation is corrected by improving gall bladder motility. ${ }^{19}$ Secondly, a proportion of gall stone patients have impaired gall bladder emptying ${ }^{20-22}$ compared with normal controls, and this emptying defect is not corrected by removal of the stones. ${ }^{23}$ Finally, groups of patients known to be at high risk for stone formation have impaired gall bladder emptying. For example, gall bladder stasis is common in patients receiving parenteral nutrition and these patients quickly form sludge and stones. ${ }^{24-26}$ This can, however, be prevented by provoking gall bladder contraction with prophylactic administration of intravenous cholecystokinin. ${ }^{27}$ Diabetes is associated with gall stone formation even when confounding variables such as obesity are taken into account, ${ }^{28}$ and the poor gall bladder motility described in these patients may have a role in their propensity for stone formation.

Erythromycin has an exaggerated effect on gall bladder fasting volume in those with diabetic autonomic neuropathy compared with either those without a neuropathy or normal subjects.
It is possible that a denervation supersensitivity in those with a neuropathy, with up regulation of the receptors responsible for the action of erythromycin, is involved. It is tempting to speculate that the cholinergic pathways play a part in this phenomenon as they have been shown to be important in gall bladder motor function, ${ }^{29}$ and at least some of the actions of erythromycin on the gastrointestinal tract are cholinergically mediated..$^{30}$ Interestingly, erythromycin does not increase the rate of gall bladder contraction in either group of diabetic patients, unlike its effect in normal subjects, or those with gall stone disease. The reason for the discrepancy between the effect of erythromycin on gall bladder fasting volume and the rate of postprandial contraction in diabetic patients with autonomic neuropathy is not clear, but suggests that the two effects may be mediated by different mechanisms.

In conclusion, we have confirmed previous work that has shown that postprandial gall bladder emptying is impaired in diabetic patients with autonomic neuropathy. In addition, we have also shown that erythromycin causes pronounced contraction of the gall bladder in the fasting state in those patients with neuropathy compared with those without, perhaps suggesting that the action of erythromycin on the gall bladder may be mediated by neural pathways.

The potential role of erythromycin as a gall bladder prokinetic agent has yet to be explored, but in patients at known high risk of gall bladder sludge and stone formation, such as those on parenteral nutrition, erythromycin may have a role in prophylaxis. We would like to thank the Joint Research Board of St
Bartholomew's Hospital and the Rahere Association for financial support.

1 Tomomasa T, Kuroume T, Arai $\mathrm{H}$, Wakabayashi $\mathrm{K}$, Itoh Z Erythromycin induces migrating motor complex in human gastrointestinal tract. Dig Dis Sci 1986; 31: 157-61.

2 Otterson MF, Sarna SK. Gastrointestinal motor effects of erythromycin. Am f Physiol 1990; 259: G355-63.

3 Catnach SM, Fairclough PD, Trembath RC, O'Donnell LJD, McLean AM, Law PA, et al. Effect of oral erythromycin on gallbladder motility in normal and gallstone subjects. Gastroenterology 1992; 102: 2071-6.

4 Sarna SK, Ryan RP, Brandon A. Erythromycin acts on presynaptic neurones to stimulate gastrointestinal motor activity. Gastroenterology 1991; 100: A490.

5 Itoh Z, Mizumoto A, Ohtawa M, Ueki S, Sekiguchi T, Omura S. Motilide (EM523) mimics motilin in interdigestive gallbladder contraction in the dog and man. Gastroenterology 1991; 100: A320.

6 Gitelson S, Oppenheim D, Schwart A. Size of the gallbladder in patients with diabetes mellitus. Diabetes 1969; 18: 493-8.

7 Keshavarzian A, Dunne M, Iber FL. Gallbladder volume and emptying in insulin-requiring male diabetics. Dig Dis $S_{c i}$ 1987; 32: 824-8.

8 Fiorucci S, Bosso R, Scionti L, et al. Neurohumoral control of gallbladder motility in healthy subjects and diabetic patients with or without autonomic neuropathy. Dig Dis Sci 1990; 35 1089-97.

9 Stone BG, Gavaler JS, Belle SH, et al. Impairment of gallbladder emptying in diabetes mellitus. Gastroenterology 1988; 95: 170-6.

10 Mitsukawa T, Takemura J, Ohgo S, et al. Gallbladder function and plasma cholecystokinin levels in diabetes mellitus. $A m \mathcal{F}$ Gastroenterol 1990; 85: 981-5.

11 Ewing DJ, Clarke BF. Diagnosis and management of diabetic autonomic neuropathy. $B M \mathcal{F} 1982 ; 285: 916-8$.

12 Everson GT, Braverman DZ, Johnson ML, Kern F Jr. A critical evaluation of real-time ultrasonography for the study
a of gallbladder volume and contraction. Gastroenterology 1980; 79: 40-6

13 Dodds WJ, Groh WJ, Darweesh RMA, Lawson TL, Kishk SMA, Kern MK. Sonographic measurement of gallbladder volume. Am F Roentgenol 1985; 145: 1009-11.

14 Everson GT, McKinley C, Lawson M, Johnson M, Kern F Jr. Gallbladder function in the human female: Effect of the ovulatory cycle, pregnancy, and contraceptive steroids. Gastroenterology 1982; 82: 711-9. 
15 Kronert K, Gotz V, Reuland P, Luft D. Eggstein M Gallbladder emptying in diabetic patients and control subjects assessed by real-time ultrasonography and cholescintigraphy: a methodological comparison. Ultrasound Med Biol 1989; 15: 535-9. 16 Sedaghat A, Grundy SM. Cholesterol crystals and the formation
of cholesterol gallstones. N Engl $\mathcal{F}$ Med 1980; 302: 1274-7.

17 Holzbach RT, Marsh M, Olszewski M, Holan K. Cholestero solubility in bile. Evidence that supersaturated bile is frequent in healthy man. $\mathcal{F}$ Clin Invest 1973; 52: 1467-79.

18 Fridhandler TM, Davison JS, Shaffer EA. Defective gallbladder contractility in the ground squirrel and prairie dog during the early stages of cholesterol gallstone formation. Gastroenterology 1983; 85: 830-6.

19 Hutton SW, Sievert CE Jr, Vennes JA. The effect of sphincterotomy on gallstone formation in the prairie dog. Gastroenterology 1981; 81: 663-7.

20 Pomeranz IS, Shaffer EA. Abnormal gallbladder emptying in a subgroup of patients with gallstones. Gastroenterology 1985; 88: 787-91.

21 Kishk SMA, Darweesh RMA, Dodds WJ, Lawson TL Stewart ET, Kern MK, et al. Sonographic evaluation of resting gallbladder volume and postprandial emptying in patients with gallstones. Am f Roentgenol 1987; 148: 875-9.

22 Fisher RS, Stelzer F, Rock E, Malmud LS, Abnormal gallbladder emptying in patients with gallstones. $\mathrm{Dig} \mathrm{Dis} \mathrm{Sc}$ 1982; 27: 1019-24.
23 Spengler U, Sackmann M, Sauerbruch T, Holl J, Paumgartner G. Gallbladder motility before and after extracorporeal shock-wave lithotripsy. Gastroenterology 1989;96: 860-3.

24 Messing B, Bories F, Kunstlinger F, Bernier J-J. Does total parenteral nutrition induce gallbladder sludge formation and lithiasis. Gastroenterology 1983; 84: 1012-9.

25 Roslyn JJ, Pitt HA, Mann LL, Ament ME, DenBesten L. Gallbladder disease in patients on long-term parenteral nutrition. Gastroenterology 1983; 84: 148-54.

26 Cano N, Cicero F, Ranieri F, Martin J, Di Costanzo J. Ultrasonographic study of gallbladder motility during total parenteral nutrition. Gastroenterology 1986; 91: 313-7.

27 Sitzmann JV, Pitt HA, Steinborn PA, Pasha ZR, Sanders RC. Cholecystokinin prevents parenteral nutrition induced Cholecystokinin prevents parenteral nutrition induced
biliary sludge in humans. Surg Gynecol obstet 1990; 170: 2531 .

28 Haffner SM, Diehl AK, Mitchell BD, Stern MP, Hazuda HP. Increased prevalence of clinical gallbladder disease in subjects with non-insulin-dependent Diabetes Mellitus. Am F Epidemiol 1990; 132: 327-35

29 Fisher RS, Rock E, Malmud LS. Cholinergic effects on gallbladder emptying in humans. Gastroenterlogy 198589 . 716-22.

30 Chausade S, Michopoulos S, Guerre J, Couturier D. Erythromycin (ERY), a motilin agonist, increases the human lower oesophageal sphincter pressure (LESP) by stimulation of cholinergic nerves. Gastroenterology 1990; 98: A335. 